\title{
Stability Analysis of Pokkali Paddy Harvester
}

\author{
H. K. Venkata Reddy ${ }^{*}$ and P. R. Jayan \\ Department of FMPE, KCAET, Tavanur, KAU, India \\ *Corresponding author
}

\section{A B S T R A C T}

\begin{tabular}{|l|}
\hline Ke y w o r d s \\
$\begin{array}{l}\text { Harvester, Paddy, } \\
\text { Pokkali, Water } \\
\text { logged, Stability }\end{array}$ \\
\hline Article Info \\
\hline $\begin{array}{l}\text { Accepted: } \\
\text { 10 November } 2020 \\
\text { Available Online: } \\
\text { 10 December } 2020\end{array}$ \\
\hline
\end{tabular}

\section{Introduction}

The Pokkali field is a unique eco system prevailing in the coastal tract of Kerala with rich bio diversity and amazing capacity to produce organic rice and shrimp alternatively. Rice plants get their nutrients from the left over of the shrimps and the shrimps in turn, feed on the stalks and decaying remnants of the rice crop. Neither chemical fertilizers nor insecticides and pesticides are used. The usual ploughing and transplantation are not required for Pokkali.In more than $90 \%$ of the single cropped lands, rice cultivation is done during the low saline phase from May/June to
September/October; the traditional prawn filtration is taken up during the high saline phase which sets in December/January.

The Pokkali paddy varieties are having early seedling vigour and attain a height of 40-45 $\mathrm{cm}$ in 30-35 days. At this stage, when field conditions become favourable the mounds are made and a few seedlings are uniformly spread on the beds in the field. The clods give anchorage to the seedlings. Generally manuring and plant protection operations are not necessary for pokkali farming systems. The crop matures at about 120 days. The ear heads alone are harvested, leaving the straw 
behind in the fields. The average yield of rice with traditional rice varieties is $1500 \mathrm{~kg} \mathrm{ha}^{-1}$. The conventional method of harvesting of pokkali paddy crop is by using sickles. The various farming operations in Pokkali paddy cultivation, the harvesting is done by women labourers by walking on the swampy and marshy inundated paddy fields at waist-deep water, which is laborious, tedious and cumbersome.

Due to these naturally adverse conditions prevailing in these lands and the nonavailability of labourers, the paddy cultivation goes on decreasing every year. Hence, there was a great demand for a suitable harvesting machine, especially for harvesting the paddy, which is under water at the time of harvest due to tidal effects. Though a number of paddy combine harvesters are commercially available, none cannot be used in such marshy water logged areas for harvesting paddy. Hence a power operated floating harvester, 'Pokkali paddy harvester' with provisions for harvesting and conveying the ear heads of water submerged paddy stalks.

\section{Review of literature}

Giles et al., (1994) conducted a study on stability of a floating body is divided in two different types, vertical and rotational. A floating body has vertical stability but its rotational stability depends upon the positions of centre of gravity (G) and centre of buoyancy (B). If $\mathrm{G}$ is below $\mathrm{B}$ the equilibrium is stable. But if $\mathrm{G}$ is above $\mathrm{B}$ the equilibrium may or may not be stable. The usual method in specification of stability of a floating body is finding the metacentre point and then comparing its position with G. The equilibrium is stable if the metacentre lies above $\mathrm{G}$.

Bansal (2005) conducted a study on a floating body. It said to be stable if it comes back to its original position after slight disturbance, two alternate moments may act on the floating body depending on the relative position of centre of gravity $(G)$ and centre of buoyancy (B).

Mohammad (2011) conducted a study on the stability of floating bodies. The potential energy of a system in stable equilibrium has a minimum value. This property is used to derive a formula that is useful in determination of stability of a floating body. It is found that a floating body is in stable equilibrium if its centre of gravity has a minimum height with respect to its related centre of buoyancy.

Omofunmi et al., (2016) conducted a study on design of water hyacinth (Eichhornia crassipes) harvester. The purpose of this study was to design a harvester for control of water hyacinth. The anatomy and physiology of the water hyacinth were used to design the machine using basic engineering procedures. The main parts of the water hyacinth harvester included an electric motor $(2.0 \mathrm{~h} \mathrm{p})$, mower disc (100 x $70 \times 7.36 \mathrm{~mm})$, shaft (26 mm diameter) with 4 blades made of stainless steel. The machine operates with capacity of 10,646 tons $\mathrm{hr}^{-1}$ at the speed of $3.04 \mathrm{~m} \mathrm{~s}^{-1}$. The capacities of the loading and delivery conveyors are 846.60 and 538.75 tons $\mathrm{hr}^{-1}$ respectively. The water hyacinth harvester is also known as aquatic scavenger. The harvester is a boat which is capable of cutting and carrying the harvested weeds to the shore. The water hyacinth harvester was designed, fabricated and tested on laboratory. The average harvesting capacity was found to be $6.5 \mathrm{t} / \mathrm{hr} / \mathrm{m}$ width of the conveyor when the traveling speed was $0.56 \mathrm{~km} \mathrm{hr}^{-1}$.

\section{Materials and Methods}

\section{Stability analysis}

Buoyancy is an upward force exerted by a fluid that opposes the weight of an immersed 
object. When the floating barge is at certain weight of harvester, it sinks to a certain depth. This allows adequate freeboard to prevent any water from getting on board. A floating object is stable if it tends to restore itself to an equilibrium position after a small displacement.

The upward buoyancy force on an object acts through the centre of buoyancy, being the centroid of the displaced volume of fluid. The weight force on the object acts through its centre of gravity.

One of the key design criteria for the harvester is the stability requirement of the floating structure. The barge has to be stable in water and unaffected by waves, wind, tides and at the same time safe for holding mass imposed on it.

\section{Transverse stability}

Transverse centre of buoyance is the point through which the force of buoyancy supporting the vessel acts vertically upwards. Transverse centre of gravity is the point through which all of the weight of the vessel including deadweight items can be considered to act vertically downwards. When the machine is upright, both the centre of buoyancy and the centre of gravity are on the centre line of the vessel.

$$
\text { i.e. } \mathrm{T}_{\mathrm{CG}}=0
$$

$\mathrm{T}_{\mathrm{CG}}=\frac{\sum \mathrm{T}_{\mathrm{mt}}}{\Sigma \mathrm{vVt}}=0$

Where,

$\mathrm{T}_{\mathrm{CG}}=$ transverse centre of gravity, $\mathrm{m}$

$\mathrm{W}_{\mathrm{t}}=$ weight of the machine, $\mathrm{t}$

$\mathrm{T}_{\mathrm{mt}}=$ transverse weight, $\mathrm{t}$

The transverse centre gravity for pokkali paddy harvester is zero. Hence the harvester is stable to floating on the water.

\section{Longitudinal stability}

If longitudinal centre of gravity and longitudinal centre of buoyancy are in the same vertical line and if there is no trimming moments on the machine,

$\mathrm{L}_{\mathrm{CG}}={ }^{\frac{\sum \boldsymbol{n}_{\mathbf{m t}}}{\sum \mathbf{w t}}}$ meters.

Where,

$\mathrm{L}_{\mathrm{CG}}=$ longitudinal centre of gravity, $\mathrm{m}$

$\mathrm{W}_{\mathrm{t}}=$ weight of the machines, $\mathrm{t}$

$\mathrm{L}_{\mathrm{mt}}=$ longitudinal weight, $\mathrm{t}$

\section{Vertical stability}

Let the $\mathrm{W}$ be the weight of the Floating body and $\mathrm{V}_{\mathrm{o}}$ be the submerged volume. Thus, downward weight of the body is balanced by the upward buoyancy force (B).

$$
\begin{aligned}
& \mathrm{B}=\rho_{\mathrm{o}} \mathrm{V}_{\mathrm{o}} \mathrm{g} \\
& \mathrm{V}_{\mathrm{CG}}=\frac{\sum V_{\mathrm{mt}}}{\sum \mathrm{Vtr}} \text { meters. }
\end{aligned}
$$

Where,

$\mathrm{V}_{\mathrm{CG}}=$ Vertical centre of gravity, $\mathrm{m}$

$\mathrm{Wt}=$ weight of the machine, $\mathrm{t}$

$\mathrm{V}_{\mathrm{mt}}=$ vertical weight, $\mathrm{t}$

\section{Results and Discussion}

\section{Stability of harvester}

The stability of Pokkali paddy harvesting. The overall size of the Pokkali paddy harvester is $6.2 \times 1.7 \times 1.7 \mathrm{~m}$ with a total weight of about $1700 \mathrm{~kg}$. A harvester is designed in such a way that to suit for fragmented Pokkali areas. The vertical centre of gravity of the scale down prototype is $0.58 \mathrm{~m}$, longitudinal centre of gravity is $2.67 \mathrm{~m}$ and transverse centre of gravity is zero. As the transverse centre of 
gravity is zero, Pokkali paddy harvester is stable to float and longitudinal centre of gravity lies near to the centre and adjacent to the front and rear side of the harvester, it become a well-balanced machine. A draft of $47 \mathrm{~cm}$ for floats, $39 \mathrm{~cm}$ for air chamber was observed for the scale down prototype of harvester of 1.70 tonnes.

\section{Centre of gravity of the components of Pokkali paddy harvester}

\begin{tabular}{|c|c|c|c|c|c|c|c|c|}
\hline $\begin{array}{l}\text { Sl. } \\
\text { No }\end{array}$ & Part List & Weight (t) & LCG (m) & VCG (m) & $\begin{array}{l}\text { TCG } \\
(\mathbf{m})\end{array}$ & LMT & VMT & TMT \\
\hline \multirow[t]{2}{*}{1} & i)Propeller (Left) & 0.0185 & 0.62 & 0.43 & -0.554 & 0.01147 & 0.007955 & -0.01024 \\
\hline & $\begin{array}{l}\text { ii)Propeller } \\
\text { (Right) }\end{array}$ & 0.0185 & 0.62 & 0.43 & 0.554 & 0.01147 & 0.007955 & 0.01024 \\
\hline 2 & $\begin{array}{l}\text { Hydraulic motor } \\
\text { for back } \\
\text { conveyer }\end{array}$ & 0.0123 & 0.06 & 0.618 & 0.38 & 0.000738 & 0.0076014 & 0.00467 \\
\hline \multirow[t]{2}{*}{3} & $\begin{array}{l}\text { i)Hydraulic } \\
\text { motor for } \\
\text { float(Left) }\end{array}$ & 0.02298 & 1.14 & 0.53 & -0.27 & 0.026197 & 0.0121794 & -0.00620 \\
\hline & $\begin{array}{l}\text { ii)Hydraulic } \\
\text { motor for } \\
\text { float(Right) }\end{array}$ & 0.02298 & 1.14 & 0.53 & 0.27 & 0.026197 & 0.0121794 & 0.006204 \\
\hline \multirow[t]{2}{*}{4} & i)Float (Left) & 0.267 & 2.815 & 0.37 & -0.54 & 0.751605 & 0.09879 & -0.14418 \\
\hline & ii)Float (Right) & 0.267 & 2.815 & 0.37 & 0.54 & 0.751605 & 0.09879 & 0.14418 \\
\hline 5 & Air chamber & 0.096 & 2.815 & 0.29 & 0 & 0.27024 & 0.02784 & 0 \\
\hline 6 & Centre conveyor & 0.139 & 1.5 & 0.618 & 0 & 0.2085 & 0.085902 & 0 \\
\hline 7 & Chassis & 0.1 & 2.21 & 0.731 & 0 & 0.221 & 0.0731 & 0 \\
\hline 8 & Engine & 0.18 & 1.681 & 1.273 & 0 & 0.30258 & 0.22914 & 0 \\
\hline 9 & Hydraulic tank & 0.137 & 2.71 & 1.05 & -0.15 & 0.37127 & 0.14385 & -0.02055 \\
\hline 10 & Diesel tank & 0.03 & 2.67 & 0.9 & 0.168 & 0.0801 & 0.027 & 0.00504 \\
\hline 11 & Chair & 0.02 & 3.071 & 1.022 & 0 & 0.06142 & 0.02044 & 0 \\
\hline 12 & Front conveyor & 0.117 & 4.91 & 0.55 & 0 & 0.57447 & 0.06435 & 0 \\
\hline 13 & $\begin{array}{l}\text { Front conveyor } \\
\text { frame }\end{array}$ & 0.059 & 4.91 & 0.55 & 0 & 0.28969 & 0.03245 & 0 \\
\hline 14 & $\begin{array}{l}\text { Hydraulic motor } \\
\text { for front } \\
\text { conveyor }\end{array}$ & 0.0123 & 3.98 & 1.02 & 0.43 & 0.048954 & 0.012546 & 0.00528 \\
\hline \multirow[t]{2}{*}{15} & $\begin{array}{c}\text { i)Hydraulic } \\
\text { cylinder (Left) }\end{array}$ & 0.006 & 4.89 & 0.523 & -0.39 & 0.02934 & 0.003138 & -0.00234 \\
\hline & $\begin{array}{l}\text { ii)Hydraulic } \\
\text { cylinder(Right) }\end{array}$ & 0.006 & 4.89 & 0.523 & 0.39 & 0.02934 & 0.003138 & 0.00234 \\
\hline 16 & Cutter bar & 0.04 & 5.8 & 0.03 & 0 & 0.232 & 0.0012 & 0 \\
\hline 17 & $\begin{array}{l}\text { Hydraulic motor } \\
\text { for cutter bar }\end{array}$ & 0.0068 & 5.7 & 0.37 & 0.6 & 0.03876 & 0.002516 & 0.00408 \\
\hline 18 & Reel assembly & 0.03 & 6.08 & 0.4 & 0 & 0.1824 & 0.012 & 0 \\
\hline \multirow[t]{2}{*}{19} & Man & 0.1 & & & & & & \\
\hline & TOTAL & 1.70 & 67.027 & 13.128 & 1.424 & 4.5078 & 0.985 & O \\
\hline
\end{tabular}

\section{Vertical stability}

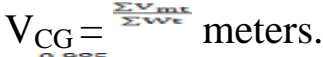

$$
\begin{aligned}
& = \\
& =0.58 \mathrm{~m}
\end{aligned}
$$

\section{Longitudinal stability}

$$
\begin{aligned}
& \mathrm{L}_{\mathrm{CG}}=\frac{\sum \mathbf{L}_{\mathrm{mt}}}{\Sigma \mathbf{w}_{\mathbf{t}}} \text { meters. } \\
& =\frac{4.50}{1.70} \\
& =2.67 \mathrm{~m}
\end{aligned}
$$


Transverse stability

$T_{C G}=\frac{\sum T_{m t}}{\Sigma w v t}$

$$
\begin{aligned}
& =\frac{\mathbf{0}}{\mathbf{1 . 7 0}} \\
& =0
\end{aligned}
$$

Fig.1 Top view

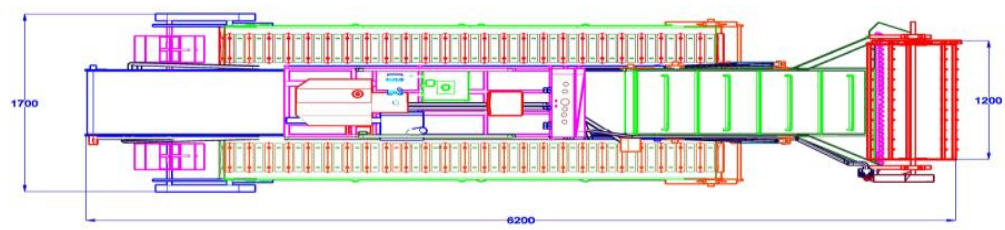

Fig.2 Side view
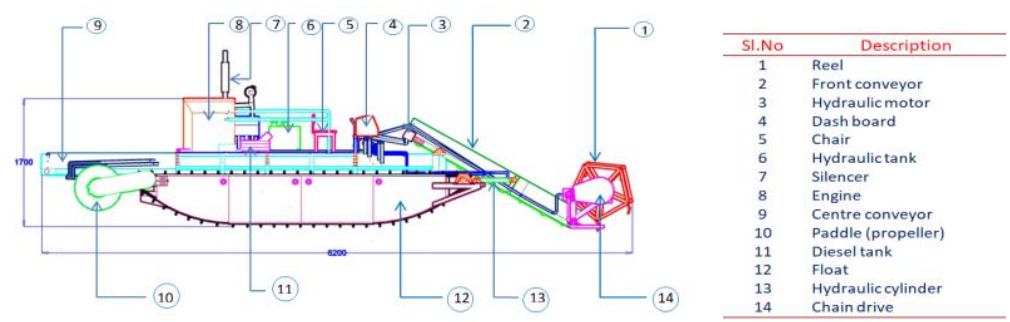

Fig.3 Isometric view

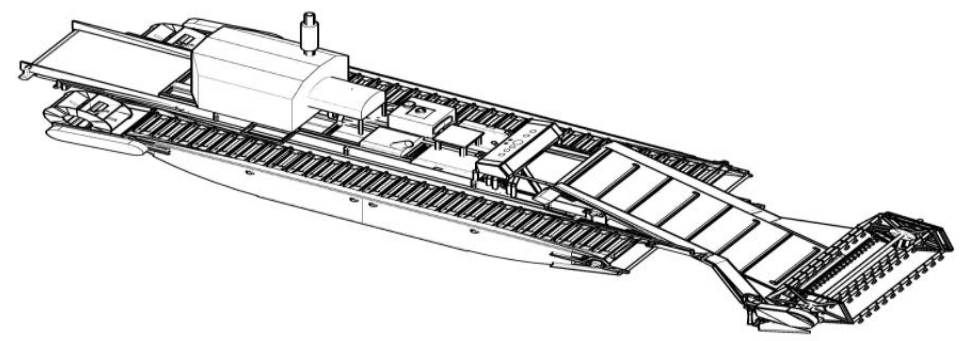

Plate.1 (a) Stable equilibrium, $M$ is above $G$ (b) Unstable equilibrium, $M$ is below $G$

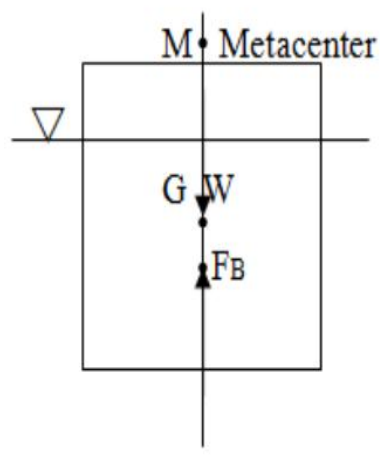

(a)

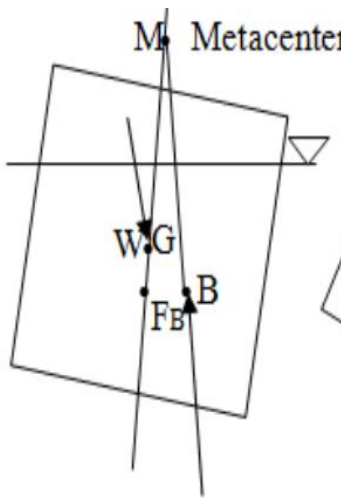

(a)

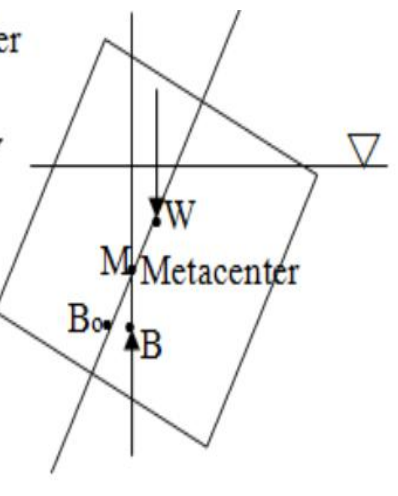

(b) 
In conclusion the conventional method of pokkali paddy harvesting, manual harvesting using sharp sickles are practiced. For the harvesting, highly labour intensive, drudgery and more time consuming operations are required. The paddy cultivation goes on decreasing every year. Hence, there was a great demand for a suitable harvesting machine, especially for harvesting the paddy. The Pokkali paddy harvester was designed for harvest panicles (ear heads) of paddy crop. The harvester was operated by a hydraulic system. The total weight of the Pokkali paddy harvester comes around $1700 \mathrm{~kg}$. The overall dimension of the harvester is $6.2 \times 1.7 \times 1.7 \mathrm{~m}$ $(\mathrm{LxWxH})$ and the stability of harvester was founded the vertical centre of gravity for harvester is $0.54 \mathrm{~m}$ and longitudinal centre of gravity is $2.67 \mathrm{~m}$ and transverse centre of gravity is zero. If transverse centre of gravity is zero, pokkali paddy harvester is stable to float. When the longitudinal centre of gravity is centre to the front and rear side of the harvester it is balanced.

\section{References}

Bansal, R. K. 2005. Fluid Mechanichs and Hydraulic Machines. Nineth edition, Laxmi Publications (P) Ltd., New Delhi-110006, India.
Giles, R. V., Evett, J. B., and Liu, C. 1994. Fluid Mechanics and Hydraulics. McGraw-Hill, Singapore. 58p.

Jayan, P.R. and Sathyanathan, N. 2010. Overview of farming practices in the water-logged areas of Kerala, India. Int. J. Agri. \& Bio. Eng. 3(4):1-16.

Kaewprakaisaengkul, C.1985. Harvesting of water hyacinth. J. of agric. Mechanization in Asia, Afr. and Latin Am.

Kanafojsi, C.Z., and Karwowski, W.C., 1976. In: Agricultural Machines, Theory and construction. Crop Harvesting Machines. United States Departments of Agriculture, and National Foundation, Washinton, D.C, II.

Koh, H.S., and Lim, Y.B., 2009. The floating platform at the Marine Bay, Singpore, Structural engineering International: $J$. of the int. Asso. For Bridge and Struct. Eng.

Mohammad Abolhassani, 2011.Rotational satiability of floating bodies. Dept. of naval architecture.

Omofunmi, O. E., Ebifemi, S. A., and Eweina, A. B. 2016. Design of Water Hyacinth (Eichhornia crassipes) Harvester. J. Sci. Res. \& Rep. 10(5): 110.

\section{How to cite this article:}

Venkata Reddy, H. K. and Jayan, P. R. 2020. Stability Analysis of Pokkali Paddy Harvester. Int.J.Curr.Microbiol.App.Sci. 9(12): 1113-1118. doi: https://doi.org/10.20546/ijcmas.2020.912.134 